\title{
Metin Erksan'ın Kuyu Filminin Mitolojiye Dayalı Bir Perspektiften Çözümlenmesi
}

\author{
An Analysis of Metin Erksan's Kuyu (Well) Based on A Mythological Perspective
}

\author{
Doç. Dr. N. Aysun Akıncı Yüksel
}

\section{Öz}

Metin Erksan Türk sinemasinın en önemli yönetmenlerinden biridir. Yarattığı sinema diliyle olduğu kadar, filmlerinde seçtiği konularla, iyiyi, kötüyü içinde barindıran gerçekçi ve derin karakterleriyle sinemamızda iz bırakmış, başyapıtları olan Yılanların Öcü (1962), Susuz Yaz (1963), Kuyu (1968) gibi filmlerle hala güncelliğini koruyan bir yönetmendir. Erksan güncel meseleler kadar, tarihi arka planı olan konulara, söylence ve mitlere de gönderme yapmamiza izin veren katmanl filmler çekmiş bir yönetmendir. Bu çalı̧̧mada Yunan mitolojisinde yer alan Apollon ile Daphne'nin hikayesinden yola çıkılarak Erksanin Kuyu filmi betimsel analiz yöntemiyle çözümlenmiştir.

Anahtar Kelimeler: Metin Erksan, Kuyu, Mitoloji, Apollon ile Daphne

\begin{abstract}
Metin Erksan is considered to be one of the most significant directors in Turkish film history. He has made his mark not only through the cinematic language that he uses, but also through his choice of subject matter. Implementing deeply formed characters with intrinsic good and evil natures, his masterpieces such as Revenge of the Snakes (Yilanlarm Öcü) (1962), Dry Summer (Susuz Yaz) (1963), and Well (Kuyu) (1968) preserve their relevance today. Erksan is a director who creates multi layered films that allow us to study them not only through current events, but also on a historic basis, with reference to legends and myths. As such, this study provides a descriptive analysis of Erksan's Kuyu film based on the Greek mythological story of Apollo and Daphne.
\end{abstract}

Keywords: Metin Erksan, Kuyu (Well), Mythology, Apollon and Daphne

\section{Giriş}

Sinema pek çok sanat dalından beslenen bir alandır. Tiyatro, resim, mimari, edebiyat sinemayla iç içe geçmiş ve sinemaya her zaman kaynak oluşturmuştur. $\mathrm{Bu}$ kaynaklardan biri de mitolojidir. İlk çağlardan bu yana insan çevresini, yaşadığı evreni, varlığının amacını kavramaya çalışmış ve bu arayış içinde belli mitler yaratmıştır. Bu mitler insan olmaya dair temel sorunlara odaklandığ 1 için üzerlerinden binlerce yıl geçmesine karşın hala güncelliklerini korumakta ve ilgi çekmektedir. Dell (2014), "Bütün mitlerin özünde daha yüce bir bilgiyi, belki de dünyaya nasıl ve niçin geldiğimiz gerçeğini saklayan bir doğaüstü dünya anlayışı yattığını" ileri sürer (s.8). Bu yüzden pek çok farklı mitolojide benzer temalara odaklanıldığ 1 gözlemlenebilir. Mitolojinin odaklandığı bu evrensel temalar ve insanın varoluşuna ilişkin sorular her zaman ilgi çeken bir alan olmasını sağlamıştır. Erhat (1978), mythos'ların sürekli değişmesinin nedeninin tek ve değişmez bir metin olmamasına, bunları ele alıp, işleyen her yeni ozan, yazar ve sanatçıyla birlikte başka bir metne dönüşmesine bağlar (s.6). Sinema da bu değişime hizmet eden sanat kollarından biridir. Özü itibariyle, hikaye anlatıcılığına dayanan ve zaman zaman kendi mitoslarını yaratan sinema mitolojik öyküleri anlatısına malzeme yapabilmekte ve böylece iç içe geçmiş bir işbirliği ortaya çıkmaktadır. Hem sinema kendi mythos'larını yaratırken eski öykülerden beslenir, hem de bunu yaparak o öyküleri boyutlandırır.

Sinemamızın en önemli yönetmenlerinden biri olan Metin Erksan'ın da zaman zaman mitolojik öykülere dayandığını söyleyebiliriz. Yönetmenin bu yönünün açıkça belli olduğu ilk filmi Susuz Yaz'dır (1963). Susuz Yaz o dönem oldukça ses getirmiş, tartışmalar yaratmış bir filmdir. Filmin yurtdışına çıkartılma-

Doç. Dr. N. Aysun Akıncı Yüksel, Anadolu Üniversitesi İletişim Bilimleri Fakültesi, naysunyuksel@yahoo.com 
s1 yasaklanmıştır. Erksan filmi, gizlice Berlin Film Festivaline gönderdiği için bütün şimşekleri üzerine çeker. Hatta neredeyse vatan haini ilan edilir. Film sansür kurulundan geçemez ve gösterimi engellenir. Berlin Film Festivaline katılması söz konusu olduğunda İçişleri Bakanlığ temsilcilerinden oluşan Özel İnceleme Kurulu Susuz Yażı Türkiye'yi temsil etmeye uygun bulmaz. Film devlet desteği ve izni olmadan festivale katılıp büyük ödül olan Altın Ayı ile ülkeye geri döndüğü zaman özel resepsiyon verilerek kutlanır (Yeres'ten aktaran Hakan, 2012, s. 261). Dönemin sansür kurulu su mülkiyeti meselesinin öne çıkmasını sakıncalı bulmuştur. Filmin gösterimine ve yurtdışında Türkiye’yi temsiline ilişkin itirazları bu gerekçeye dayanmaktadır. Festival jürisi ise filmi Habil ve Kabil'in öyküsünün çağdaş bir uyarlaması olarak okumuş ve değerlendirmiştir. Eğer bir Metin Erksan filminden söz ediyorsak bu tür farklı okumalara rastlamak olağandır. Çünkü onun filmleri çok katmanlıdır. Farklı ve derin okumalara izin verir. Tipkı Kuyu'da (1968) olduğu gibi.

Kuyu hala güncelliğini koruyan bir konuya sahiptir. Bugün Türkiyede kadına yönelik her türlü şiddetin, ama özellikle ölümle sonuçlanan şiddet temel sorunlardan biri olarak karşımıza çıkmaktadır. Kadınlar, yaşı, milliyeti, sosyal konumu fark etmeksizin cinsel saldırıya uğrayabilmektedir. Film öncelikle bu konuda bir okuma yapmaya izin vermektedir. Nitekim Kuyu'ya dair yapılmış çalışmaların bir çoğunda filmin açılış sekansında Kuran’ın Nisa suresinin 19. ayetinden alıntılanan "Kadınlara iyi davranın" sözüne vurgu yapılmakta, ataerkil sistem içinde kadının uğradığ nılmakta ve Erksan’in Yilanların Öcü ve Susuz Yaz’da da öne çıkardığı mülkiyet kavramı tartışılmaktadır (Sözen, 2012; Taş Öz, 2012; Sim, 2009, Altıner, 2005). Yukarıda da vurgulandığ 1 üzere film bu okumalara izin verecek yoğunluktadır. Kaldı ki Metin Erksan senaryoyu gerçekte yaşanmış olan bir olaydan yola çıkarak yazmıştır. Dolayısıyla, filmin öyküsü çok somut, yaşanmış bir şiddet ve işkenceye dayanmaktadır. "Bir adam bir kadını beş kere dağa kaçırmış, hapse giriyor, çıkıyor, gene kaçıyor. Bir tutku. Beşincide dağlarda gezerken bir kuyuya geliyorlar, adam iniyor, kadın da üstünü taşla örtüyor. Hatta kadını hapiste ziyarete gidecektim ama, olmadı." (Altıner, 2005, s. 79). Metin Erksan bu olayı filme uyarlarken bazı değişiklikler yapmıştır. Gerçek olay çok daha marazi, hastalıklı iken o kaçırılma sayısını beşten üçe indirmiş, kadının gerçek hayatta olduğu gibi jandarmaya teslim olması yerine ise kuyunun başında intihar etmesiyle filmi sonlandırmıştır. Tüm bunlar kadın sorununa ilişkin çok şey söylemeye izin veriyor. Ancak bu çalışmada, bu odak noktasından uzaklaşılarak, Susuz Yaz'da Habil ve Kabil öyküsünün izinin sürülmesi gibi, mitolojik bir arka plan arayışına gidilecektir. $\mathrm{Bu}$ noktada filmle bağlantı kurulmaya çalışılacak öykü Yunan mitolojisinde oldukça iyi bilinen Apollon ile Daphne'nin hikayesi olacaktır.

\section{Araştırmanın Yöntemi Amaç}

$\mathrm{Bu}$ çalışmanın amacı seçilen örneklem üzerinde Metin Erksan sinemasının çok katmanlılığına ilişkin yeni bir boyut katmaktır. Bu doğrultuda, yönetmenin Kuyu filmiyle, Yunan mitolojisindeki Apollon ve Daphne hikayesi arasındaki paralellikleri ortaya koymak amaçlanmaktadır.

\section{Örneklem}

Bu çalışmada yargısal örnekleme yöntemine başvurulmuştur. Yargısal örneklemede "örneklemi oluşturacak birimlerin seçiminin seçimi yapan kişinin arzu ve düşüncelerine göre deneyimlerine dayanarak yapılması söz konusudur" (Özmen, 2000, s.41). Dolayısıyla, Metin Erksan’n filmleri arasında daha önce mitolojik bir öykü ile bağlantı kurulmamış olan ve böyle bir okumaya izin verdiği düşünülen Kuyu filmi, söz konusu yargıya dayanılarak seçilmiştir.

\section{Yöntem}

Çalışmada Kuyu filmi betimsel analiz yöntemiyle ele alınıp, incelenmiştir. Betimsel analiz, çeşitli veri toplama teknikleri ile elde edilmiş verilerin daha önceden belirlenmiş temalara göre özetlenmesi ve yorumlanmasını içeren bir nitel analiz türüdür. Bu analiz türünde araştırmacı görüştüğü ya da gözlemiş olduğu bireylerin görüşlerini çarpıcı bir biçimde yansıtabilmek amacıyla doğrudan alıntılara sık sık yer verebilmektedir. $\mathrm{Bu}$ analiz türünde temel amaç elde edilmiş olan bulguların okuyucuya özetlenmiş ve yorumlanmış bir biçimde sunulmasıdır (Yıldırım ve Şimşek'ten aktaran Özdemir, 2010, s. 336). 


\section{Bulgular ve Yorum}

Kuyu kredilerin akmaya başladığı açılış sekansındaki, kuyunun içinden çekilmiş görüntüyle kadınlığa ve dişiliğe gönderme yaparak başlar. Kuyunun dar, karanlık ve ıslak iç çeperi kadın cinsel organını çağrıştırır. Anlarız ki bir kadın hikayesi beklemektedir bizi. Sinemada, bir delik her zaman dramatiktir, der Bointzer (2011, s. 34). Bir kuyudan, anahtar deliğine, kurbanın içine atıldığı asansör boşluğundan, açık bir cinsel organa kadar her delik dramatik bir etki yaratır sinemada ona göre. Erksan'ın filminde de kuyu filme adını verir. Görselliği kadınla bağ kurmamızı kolaylaştırır. Ama tekinsiz bir görüntüdür bu. Zaten Kuyu da iç ferahlatan bir film değildir. Başından sonuna kadar izleyicisini huzursuz eder.

Yönetmen sözü çok uzatmadan daha ilk sahnede derenin içinde giysileriyle serinlemekte olan Fatma’yla tanıştırır izleyicisini.

\section{Eskiden çok eskiden yeryüzünde \\ Güzelliği dillere destan \\ Bir su perisi vardı adı Defne \\ Upuzun saçları altın sarısıydı \\ Dolaşırdı kuytu ormanlarda bütün gün \\ Defne trmak tanrısının kızıydı (Anday'dan aktaran Erhat 1978, s. 88)}

Anday, Defne ve Apollon arasındaki öyküyü böyle dizelere döker. Belki Fatma’nın saçları altın sarısı değildir ama güzel olduğu aşikardır. Fatma’nın dereye bir zorunluluk nedeniyle girmediği rahatlıkla anlaşılır. Derede bulunuş nedeni tamamen keyfidir. Fatma, bir su perisinin suyu sevmesi, onunla oynaması gibi derede zevkle zaman geçirmektedir. Kısa bir süre sonra Osman'la tanışırız. Sırtında çiftesi, belinde tabancasıyla bir avcı olduğunu anlarız Osman’n. Filmin bir başka sahnesinde ise tek atışla bir ördeği vurduğunu görürüz. Bu konuda şüphe yoktur; iyi avcıdır. Osman sudaki kızı gözetler. Bakışlarındaki tutku sezilir. Osman’ fark eden Fatma hemen bir çalılığın arkasına gizlenir. "Ya kendi rizanla karım olursun ya da ölünü götürürüm” der Osman. Tehdit eder Fatma’yı. Fatma'nın dere kenarındaki giysilerini toplayarak suya girer. Fatma korkarak kaçar Osman'dan.
Siram siram boynu bükük yavuklu

Bekleyedursun bir yanda

Defne başıboş gönlü özgür

Inatçı, hırçın ve gururlu

Koşup dururdu ormanda

"Benim geyiğim sen, kuzum sen

Kuzu kurttan korkar, geyik aslandan

Güvercin kartaldan kaçar

Ben sana act vermek istemem

Ayaklarını kanatmasın çalılar

Yavaşla biraz düşeceksin

Geçtiğin keçi yolları dar

Dur hele kaçma benden

Sevgimdir seni kovalayan..." (Anday'dan ak taran Erhat 1978, s. 89)

Osman da Fatma da inatçıdır. Osman Fatmàyı elde etmek için, Fatma da hiçbir zaman gönüllü olarak onun karısı olmamak için adeta ant içmiştir. Apollon ile Daphne'nin öyküsünde de benzer bir durum vardır. Onların öyküsünde Eros’un parmağı vardır. Çok iyi bir avcı olan Apollon, bir gün henüz çok genç olan Eros'u elinde ok ve yayla görür. Eros'la alay eder. Apollon'a göre ok ve yay güçlü tanrıların elinde olmalıdır. "Kurbanlarını yaralayan sadece senin okların değildir" diye yanıtlar onu Eros. İntikam almayı kafasına koyar. İki ok vardır elinde. Biri isabet edene sonsuz tutkulu bir aşk ve arzu verecektir, diğeri de ondan nefret etmeyi. Aşk oku Apollon’a isabet eder, nefret oku ise Daphne'ye. Su perisi Daphneye vurulan Apollon'un gözü ondan başkasını görmez. Takıntılı biçimde, onu ikna etmeye çalışarak kovalar durur su perisini. Daphne de aynı kararlılıkla Apollon'dan kaçar. Tipkı Artemis gibi bakire kalmak için ant içmiş olan Daphne karşısında hiç şansı yoktur Apollon'un. Kovalamaya başladıktan sonra kim olduğunu da açıklar kızın gözünü boyamak için. O tanrıların en sevileni, en beğenileni Apollon'dur. Niye kaçmaktadır ki Daphne? (Pouzadoux, 2004, s. 53-57).

Daha sözünü bitirmeden avcl

Korkak adımlarla uzaklaştı Defne

Kaçarken daha bir güzelleşti de 
Ardinda tir tir titreyen avcl

Tavşan kovalayan hırslı bir tazı

Gibi düştü Defne’nin peșine

"Ben de yılmadan kovalayacağım

Büyülediğin kimmişöğren

Ben ne bir dağll ne bir çobanım

Oklarindan sakinılmaz tanriyım

Koca Zeus'tur babam

Geçmişi, bugünü, geleceği

Benimle bildi herkes, benimle bilir

Saz tellerine ben verdim seslerini

İlaçlar yaptım yabanıl otlardan

Ama bana çare değil şimdi hiçbiri

Kimden kaçıyorsun öyle sen

Asil sensin benim avcim

Beni sen vurdun can evimden" (Anday'dan aktaran Erhat 1978, s. 89)

Osman’n Fatma’ya tutkusu da kendini beğenişi, özgüveni de Eros'un okuyla kendini kaybeden Apollon'dan farksızdır. "Sana doyamıyorum Fatma", der. "İki de bir canım seni çekiyor. Çok güzel avratsın. N’olur sen de sevsene beni biraz". Tipkı Eros'un nefret okuyla vurulmuş Daphne gibi istediği tepkiyi vermez Osman’a Fatma. İsyan eder Osman. Kendini beğendiği çok açıktır Osman'ın. "Nere mi beğenmiyorsun benim? Başka karılar deli oluyor bana”. Üstünlüğünün altını dine dayanarak çizer. Kadın kısmının erkeğin aşık kemiğinden yaratıldığını söyler. Kadın erkeğe göre daha değersizdir Allah’n gözünde. Bir bildiği vardır elbette yaratanın. Ama tüm bunlara karşın Fatma geri adım atmaz. Osman onu hiçbir şekilde ikna edemez. Jandarma tarafından yakalanıp, cezasını çektikten sonra Fatma’yı ikinci kez kaçırır. Onun için yıllarca hapiste yattığını yine de vazgeçemediğini, karısı olmasını istediğini söyler. Çıplak biçimde ağaca bağladığı Fatma, bakire kalmaya ant içmiş Daphne gibi meydan okur Osman’a: "Senden de bütün erkeklerden de iğreniyorum. Benim kendimi değil, ölümü kaçırıyorsun". Fatma fiziksel olarak bakire değildir belki ama zihnen Osman'la bir bağ içinde değildir. Ona karşı bir sevgi besleyemez. Fatma, onu evlendirmek istedikleri yaşlı adamla da, daha sonra oturak alemlerinin yapild1ğ1 meyhanedeki erkeklerle de ilişki kuramaz. Onun kendini yakın hissettiği tek erkek hapishaneden firar etmiş olan Taşpınarlı idamlık Mehmet'tir. Yaşlı adamla evlendirilecekken dügününden kaçan Fatma, kendini asmaya çalışır. Onu kurtaran Mehmet olur. Mehmet diğer erkeklerin aksine Fatma’yı rahat birakır. Akarsuda yıkandıkları sahnede Mehmet yaklaştıkça kaçar Fatma. Ama en sonunda rıza gösterdiği sezilir Mehmet'in ilgisine. Onu sevdiğini anlarız. Nitekim Mehmet jandarmayla girdiği çatışmada vurulup öldügünde ardından yas tutar Fatma.

Ailesi tarafından reddedilen Fatma ortada kalır ve oturak alemlerinin yapıldığı bir meyhanede sakilik yapmaya başlar. Osman ise hapistedir. Hapiste onu ziyaret eden ve Fatma’yı bırakmasını öğütleyen annesine çıkışır Osman: "Fatma’yı bırakamam ana. Ciğerime işlemiş o kız benim”. Osman’nki önünü alamadığ 1 hastalıklı bir tutkudur. Hapisten çıktıktan sonra önce Fatmayyla evlenmeye çalışan yaşlı adamı bulur. Evire çevire döver adamı. Ona ait olan kadına nasıl göz koyabilmiştir. Sonra da Fatmảnın izini sürer ve çalıştığı meyhaneyi basıp üçüncü kez kaçırır Fatmàyı. Halâ dilediği Fatma’nın rıza göstererek onunla evlenmesidir. Üçüncü kez Fatma’nın beline ip bağlayarak sürüklemeye başlar. Uçsuz bucaksız, neredeyse fantazmagorik bir boşluk olarak tanımlanacak çorak bir arazinin ortasinda bir kuyuya denk gelirler. Osman hem serinlemek hem de su içmek için kuyuya iner. Bir an kararsız kalan Fatma yerden aldığı büyükçe bir taşı Osman’’n başına atar. Neye uğradığını şaşıran Osman çırpınmaya başlar. Sonra yine bir taş yardımıyla Osman'ın kuyuya indiği ipi keser ve üzerine taş atmaya devam eder. Daha sonra da kuyunun üstünü taşla kapatır. Ardından kuyunun üstünde kendini asar.

\section{Gücü kalmamıştı artık Defne’nin}

Koşamıyordu kaçamıyordu

Sapsarı, yalvardı babasına

"Cezasını çekiyorum güzelliğimin

Irmakların gücü de sen gibi tanrısalsa

Ne yap yap değiştir beni

Başka bir biçime koy baba"

Yalvarması daha bitmemişti ki

Bir gevşeklik sardı her yerini

Örtüldü göğsü yaprakla

Kolları, saçları dal oluverdi. 
Avcı kollarına aldığı zaman

Kalbi çarpiyordu Defne’nin

Taze yapraklarm altından.

Yazık dedi tanrı çok yazık (Anday'dan akta ran Erhat 1978, s. 89)

Fatma, kupkuru arazinin ortasında buldukları su kaynağında, kuyuda kurtuluşunu bulur. Hem Osman'dan kurtulur hem de yeryüzündeki yaşamına son verir. Ancak onun ölümü Daphne’ninki gibi kutsanmayacaktır.

Öte yandan, Kuyu'nun sinematografik olarak da masalsı bir dile sahip olduğu ileri sürülebilir. Film ger-

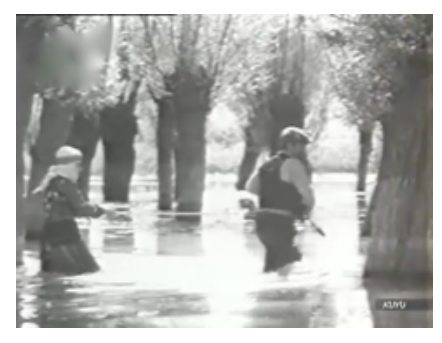

Şekil 1

Masal anlatılarında sık sık yinelenen dere tepe düz gitmek sözcüğü Kuyu'da görsel olarak karşımıza çıkar. Fatma’nın annesinin Osman’ın annesiyle tartıştı-

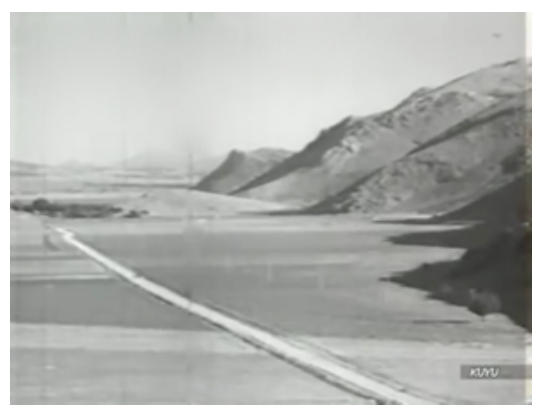

Şekil 3

Her ne kadar karakterlerin giysileri, jandarmalar gibi olayın geçtiği yer ve zamana ilişkin ip uçları olsa da filmin görsel kodları gerçekten uzak masalsı bir izlenim yaratır. Fatma ile Osman’ın kuyuya varışları da böylesi bir görüntüyle verilir (Şekil 4). Tüm bu görüntüler, hem dramatik, hem masalsıdır. Filmin çek bir olaya dayansa da Metin Erksan filmin sinematografisinde masalsı bir atmosfer yaratmayı başarır. Filmin bu yanı söz konusu gerçeklikten uzaklaşarak Apollon ile Daphne’nin öyküsüne yaklaşmamıza yardimci olur.

Pek çok filminde olduğu gibi Metin Erksan Kuyu'da da suyun tekinsiz yanını öne çıkarır. Su, Osman’n dediği gibi günahlardan arındırır belki ama aynı zamanda ölüm de getirir. Suya övgüler yağdıran Osman’n ölümü de suyla olur. Filmde Osmanın Fatmàyı ilk kaçırışında içinde yürüdükleri sular altında kalmış alan bu tekinsizliğin altını çizerken bir taraftan da masalsı bir görünüm verir. (Şekil 1)

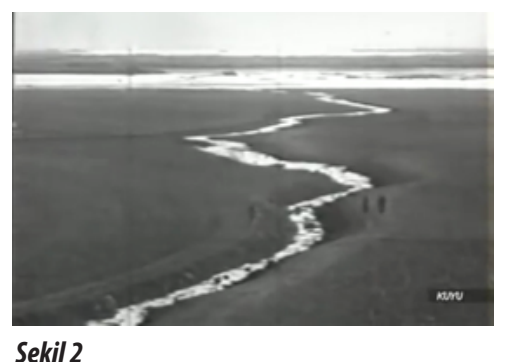

ğ1 sahne (Şekil 2), Osman’’n jandarma tarafından götürüldügü sahne söz konusu masal sözünü anımsatır (Şekil 3).

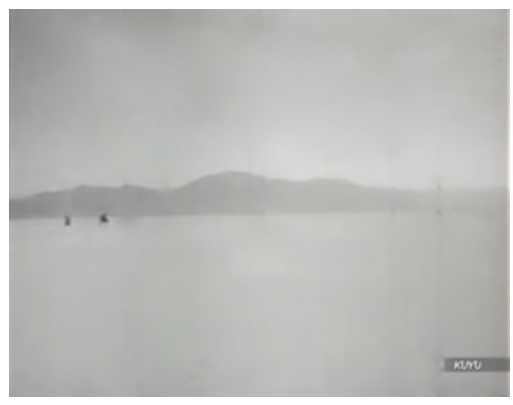

Şekil 4

ilham aldığ gerçeklikle tezat oluşturur. Bu görüntüler sanki başka bir evrenden, en iyi olasılık, bir masal diyarından gelmeymiş gibi durur. Başka deyişle, yalnızca mitolojik bir öyküyü anımsattığ 1 için değil, görselliği ile de farklı çağrışımlara izin verir Kuyu. 


\section{Sonuç}

Hiç kuşkusuz Apollon ile Daphne arasındaki kaçma kovalama Fatma ile Osman'in arasında yaşananlardan çok farklı bir boyuttadır. Mitolojik öykü hem tanrısal hem de eril güce sahip Apollon'un aşık olduğu Daphne’nin çaresizliğini romantik bir vurguyla sonlandırır. Aşık olduğu su perisi defne ağacına dönüşünce, hoş kokulu yapraklarını taç yapar başına Apollon. Fatma ve Osman arasındaki ilişkide böyle bir romansa yer yoktur. Onların sonu ne bir söylenceye yakışır ne de mutlu sonla biten bir masala. Düpedüz tahakküm altına alma, aşk adı altında kadına zorla sahip olma, marazi, hastalıklı bir tutku vardır. Ancak, Metin Erksan gibi çok yönlü bir yönetmenin öykünün yalnızca üst katmanıyla sınırlı kalamayacağ1, daha evrensel bir arayış içinde olabileceği düşüncesi bu iki anlatı arasında, mitolojik öykü ve film arasında, bir bağ kurmayı kolaylaştırmaktadır. Böylece film, hem kadına yönelik şiddetin en ağır örneklerinden birini perdeye aktardığı için, hem de çok bilinen mitolojik bir öyküyü çağrıştırdığı için hala güncelliğini korumayı başarmaktadır.

Filme adını veren ve cinsel organını çağrıştıran kuyu, o tekinsiz delik Osman'ın mezarı olur. Kadın eliyle, kadınca bir mezarın içine, üzeri taşlarla kapatılarak gömülür Osman. Belki Apollon gibi sevilen bir tanrı değildir ama onun gibi eril gücü temsil eden, zorba bir aşıktır. Bu gücü gömer Fatma. Ama bilir ki ataerkillik yalnızca Osman'da cisimleşmemiş, dört bir yanını kuşatmıştır. Kendisini kurtarması için babası nehir tanrisı Peneus'a yakaran Daphne gibi sudan alır gücünü. Buldukları kuyu hem Osman'dan hem de başına geleceklerden kurtulmasını sağlar. Daphne gibi bir nehir kıyısında ağaca dönüşemez Fatma. Ama onun da zorba erkek egemenliğinden kurtuluşu bir su kaynağı ile olur. Böylece filmin mitolojik öyküyle arasındaki benzerlikler pekişir. Başa dönecek olursak, Azra Erhat'in mythos'ların her yeni sanatçıyla birlikte değişime uğradığı ve evrildiği savının doğru olduğunu söyleyebiliriz. Çok bilinen Apollon ile Daphne’nin öyküsü doğrudan bir uyarlama ile olmasa da Metin Erksan'ın filminde boyutlanarak aktarılmıştır. Bu da mythos'ların evrenselliğini ve sınırsızlığını bir kere daha kanitlamaktadır.

\section{Kaynakça}

Altıner, B. (2005). Metin Erksan Sineması. İstanbul: Pan.

Bonitzer, P. (2011). Kör Alan ve Dekadrajlar. İstanbul: Metis.

Dell, C. (2014). Mitoloji-Hayali Dünyalara Eksiksiz Rehber. İstanbul: Yapı Kredi.

Erhat, A. (1978). Mitoloji Sözlüğü. İstanbul: Remzi.

Hakan, F. (2012). Türk Sinema Tarihi. İstanbul: İnkılap.

Erksan, M. (Yönetmen/Senarist). (1968). Киyu [Film]. Türkiye. https://www.youtube.com/ watch?v=JI8a5vfwb2Y

Özdemir, M. (2010). Nitel veri analizi: Sosyal bilimlerde yöntembilim sorunsalı üzerine bir çalışma. Eskişehir Osmangazi Üniversitesi Sosyal Bilimler Dergisi, 11(1), 323-343.

Özmen, A. (2000). Uygulamalı araştırmalarda örnekleme yöntemleri. Eskişehir: Anadolu Üniversitesi.

Pouzadoux, C. (2004). Masal ve Efsaneler-Olympos Tanrıları. E. Sunar (Çev.) İstanbul: Say.

Sim, Ş. (2009). Türk Sinema Tarihỉnde İlk Üçleme, Metin Erksan'dan Mülkiyet Üçlemesi: 'Yllanların Öcü', 'Susuz Yaz', 'Kuyu'. İstanbul Aydin Üniversitesi Dergisi, Yll 1 Sayı 3-4, sayfa 171, 196, 2009 Elektronik versiyon http://iaud.aydin.edu.tr/makaleler/ yil1sayi3-4/IAUD_Yil_1_Sayi_3-4_Makale_10.pdf

Sözen, M. (2012). Kadın Oluşa Yakılan Ağıt. F. Masdar (ed.), Metin Erksan ve Sineması Üzerine (s.69-88). Ankara: Dünya KIV.

Taş Öz, P. (2012). Metin Erksan Filmlerinde Mülkiyet Meselesi: Yllanların Öcü, Susuz Yaz, Kuyu. F. Masdar (ed.), Metin Erksan ve Sineması Üzerine (s.109135). Ankara: Dünya KIV. 